\title{
Cholera in Guinea: The Implication for Safe Water Sources and Sanitations
}

\author{
Keita Mamady ${ }^{*}$, Sylla Mafoule ${ }^{2}$ \\ ${ }^{1}$ Department of Epidemiology and Health Statistics, School of Public Health, Central South University, Changsha, \\ China \\ ${ }^{2}$ School of Business, Central South University, Changsha, China \\ Email: ${ }^{*}$ kethmohawassdeh@gmail.com
}

Received 27 May 2014; revised 28 June 2014; accepted 16 July 2014

Copyright @ 2014 by authors and Scientific Research Publishing Inc.

This work is licensed under the Creative Commons Attribution International License (CC BY).

http://creativecommons.org/licenses/by/4.0/

(c) (i) Open Access

\begin{abstract}
Objectives: To lay stress upon the importance of adequate water and sanitation in the prevention of cholera in Guinea. Methods: The data on deaths and cases of cholera in Guinea from 2000 to 2011 were downloaded from the WHO Official website. The data on deaths and cases of cholera outbreak which occurred in Guinea from 02 February to 15 October 2012 were collected from the Guinean Ministry of Public Health. The cholera index case is confirmed by a laboratory test. Cholera cases were defined as individuals over one year old who had had watery stools with or without vomiting. Cholera incidence and case fatality rates between different areas of cholera occurrence in the country over time were computed. Results: Over the overall 12-year period (2000-2012), the case fatality rate showed a somewhat sign of slight rising trend when the incidence rates increased rapidly. During the seven consecutive years of cholera outbreaks in Guinea, between 2003 and 2009, the most affected areas were Conakry, Dubreka, Coyah, Boffa, Forécariah, Guékédou, Dalaba and Télimélé. In 2012, Cholera outbreak resulted in an incidence rate of 23.23 per 10,000 population and a case fatality ratio (CFR) of approximately $1.8 \%$. Cases and deaths were reported in 12 prefectures out of 34: Conakry, Coyah, Forecariah, Fria, Boffa, Dubréka, Boké, Mamou, Kindia, Kankan, Kerouané and Dabola. Conclusion: Cholera is an important health problem in Guinea. Any earnest attempts to improve water and sanitation alongside with promotion of good hygienic practices will likely ward off the threat of cholera in the country.
\end{abstract}

\section{Keywords}

Guinea, Cholera, Water, Sanitations, Public Health

${ }^{*}$ Corresponding author. 


\section{Introduction}

Cholera has throughout history wreaked havoc on the world's people and still remains a global threat, especially in African countries [1] [2]. By 2008, 179,323 (94\%) of the reported 190,130 cholera cases and 5074 (99\%) of 5143 cholera deaths reported to the WHO occurred in Africa [3]. In 2009, a total of 45 countries reported 221,226 cases and 4946 deaths; for both, >98\% occurred in sub-Saharan Africa [4].

In Guinea, Cholera has been first introduced during the course of the seventh pandemic in 1970 [5]-[7]. Since then the disease has been persistent in the country, with at least 8 years intermittent outbreaks, until occurring annually between 2003 and 2009 [8]. Before 1994, outbreaks of cholera were confined to the cities on the coastline; but now it is occurring over a very wide area of the country affecting a large number of people. In 2008, Guinea reported the fourth highest CFR 6.24\% worldwide. Vibrio cholerae serogroup O1 biotype El Tor was the causative agent of all these outbreaks [9]. From 2000 to 2011, Guinea Ministry of Health officially reported a total of 19,712 cases and 865 deaths to the World Health Organization (WHO) [3] [10]-[18]. A lot of efforts have been put into cholera case management, and health education of the population in Guinea, but long-term intervention like improve water and sanitation which should be the mainstay of cholera control measures has been lax [19] [20].

Cholera is most commonly caused by ingestion of water or food contaminated with fecal matter [21] [22]. The importance of fecal-oral transmission in cholera epidemics is also supported by recent time series models fitted to the endemic dynamics of cholera in Bangladesh [23] [24]. A recent study was focused on oral cholera vaccines as a tool to control cholera outbreaks and spreads in Guinea since the provision of safe water and proper sanitation remain out of reach in many low-income countries like Guinea, economy of which country remains one of the poorest in the world with a per capita GDP of US\$ 560 [25] [26]. In case that the role of carriers in the transmission of cholera is overlooked, the areas hitherto invaded will be the potential foci of infection for a long period including a greater danger of continuous spread, with variable severity during sporadic and periodic outbreaks. The recent cholera outbreak in Guinea in 2012 that resulted in the reporting of a total of 7147 cases of cholera and 127 deaths: a case fatality ratio (CFR) of approximately 1.8\% [27] was caused by a new generation of cholera strains - atypical variants of vibrio cholerae O1 El Tor. The new strains secrete a toxin severer than usual strains, creating a more virulent illness-with harsher symptoms and a higher infection rate [28]. In addition to human suffering and lives loss, cholera outbreak causes panic, disrupts the social and economic structure and can impede development in the affected communities due to its rapid spread and ability to cause large epidemics [15] [29] [30].

This study is the first of its category to have placed special emphasis on purveying safe water and adequate sanitation to the community as well as the promotion of better hygiene as key factors to reducing the risk of future outbreaks of cholera, and, if those solutions are widely implemented, these measures could greatly improve health and socio-economic outcomes in Guinea. This paper aims to examine the prevention and control measures of cholera in Guinea.

\section{Methods}

\section{Study site}

The Republic of Guinea is located in West Africa, between $7^{\circ}$ and $12^{\circ}$ latitude north and $8^{\circ}$ and $15^{\circ}$ longitude west, with a coast line of $300 \mathrm{~km}$ on the Atlantic Ocean. It is bordered by Guinea-Bissau to the north-east, by Senegal and Mali to the north and north-east, by Côte d'Ivoire to the east and by Liberia and Sierra Leone to the south. The country features a tropical climate, alternating between dry seasons (from November to April) and rainy seasons (from May to October), depending on region and altitude. It should be noted that the country has one of the densest hydrographic networks in the area [31]. Guinea's population was estimated at 11,121,231 inhabitants in 2012, on the basis of estimates relying on the 1996 census and an area of 246,000 square kilometers (94,981 sq mi) [32].

\section{Data}

The data on deaths and cases of cholera on an annual basis for the whole of Guinea (2000 to 2011) were ascertained from the WHO Official website (http://www.who.int/cholera/statistics/en/index.html). The data on deaths and cases of cholera outbreak occurred in Guinea from 02 February to 15 October 2012 were collected from daily notification of the infectious disease database established at the Guinean Ministry of Public Health. The public health system in Guinea features a pyramidal structure, comprising two national hospitals (teaching 
hospitals), seven regional hospitals, 26 prefectural hospitals, 8 communal medical centers, 390 health centers, and 628 health posts [33].

In Guinea, cholera surveillance is included in national "Integrated surveillance system for disease and response”. Cholera data are collected in health facilities by trained health care professionals and weekly sent to cholera surveillance focal points in each of the seven administrative regions. The Prefectural Department of Health compiles the data and then forwards them to the Regional Department of Health which summarizes and transmits it to the Department of Health Information at the Ministry of Health, where a team of scientific community and specialized health experts validate the data. This information is shared with other partners (WHO, UNICEF, NGOs) in a weekly base during the meeting of the Cholera Task Force. During cholera outbreaks, the health centers in epidemic areas are assigned as cholera transit centers, where suspected cholera patients are administered rehydration solution and cholera treatment. During the same period, the national crisis committee, chaired by the Minister of Health, meets once a week for an update on the cholera epidemiological situation [33].

\section{Case Definition}

During each cholera outbreak, the cholera index case is confirmed by a laboratory test. After the index case is confirmed by a laboratory test, subsequent cholera cases are identified by clinical diagnosis in accordance with the surveillance guidelines of the national "Integrated surveillance system for disease and response" at the Guinean Ministry of Health. The guidelines defined cholera cases as individuals over one year old who had had watery stools with or without vomiting. In non-epidemic periods, a cholera case is defined as an individual over one year of age who develops severe dehydration or dies as a result of severe watery diarrhea [9].

\section{Analysis}

To assess the morbidity and mortality burden due to cholera, we used the cumulative incidence rate and case fatality rate respectively.

The cumulative incidence rate was calculated as new cases of cholera occurring during a given time period divided by the population size during the same time period $\times 10,000$.

We calculated the case fatality rate as the number of cases died with cholera divided by the clinically diagnosed cholera cases $\times 100$.

We analyze the trend of cholera morbidity and mortality from 2000 to 2012 except for the year 2010 for which the data were not available (Table 1). The available cholera outbreak data in Guinea from 2003 to 2009 and that for 2012 were used to show the burden of cholera by geographic areas in Guinea. We also used the epidemic curve to display the course of cholera outbreak that occurred in Guinea in 2012. It is of immense importance to examine the difference of cholera incidence and case fatality rates between different areas of cholera occurrence in the country as well as the variation of incidence and the case fatality rates in different epidemic stages. The value in conducting such analyses is that the findings may serve as the basis for the decision making of how to prevent and control cholera among populations.

\section{Results}

Over the 12-year period (Table 1), there were 26,859 cases and 992 deaths resulted from cholera in Guinea. The average number of cases and deaths reported over that period were 2238.3 and 82.7 respectively. Cholera case fatality rates increased from 2000 to 2002, but unevenly decreased from 2002 to 2011, then showed a somewhat sign of slight rising trend in 2012. Cholera incidence rates drop at lower rates between 2000 and 2003, but rise between 2003 and 2007, then drop again from 2007 to 2011; the incidence rates finally rise rapidly from 2011 to 15 October 2012.

Table 2 shows the cumulative incidence and case fatality rates of cholera yearly outbreaks in Guinea between 2003 and 2009 by prefectures. The cities that registered the highest cholera case fatality rates by descending order were: Télimélé 40.4\%, Lélouma 36.1\%, Dabola 34.0\%, Lola 29.7\%, Kankan 26.6\%, N’zérékoré 11.3\%, Pita 9.7\%, Kissidougou 9.3\%, Dalaba 7.4\%, and Guékédou 7.0\%. Most of the lower case fatality rates were found in the prefectures of those administrative regions clustered on the coastal strip such as Boke, Kindia and the special zone of Conakry. As opposed to the case fatality distributions by prefectures, the cumulative incidence rate per 10,000 population was higher for Conakry and its surrounding administrative regions (Boke, Kindia) on the coastal strip than the remote regions like Labé, Mamou, Faranah, Nzérékoré and Kankan except for the city of Faranah and Gueckedou (Table 2). A number of 7 outbreaks occurred annually in Guinea, between 2003 and 
Table 1. Cholera cases and deaths reported by Guinea to the World Health Organization, from 2000 to 15 October 2012.

\begin{tabular}{cccccc}
\hline Reporting Year & Number of Cases & Number of Death & $\begin{array}{c}\text { Estimated } \\
\text { Populations }\end{array}$ & $\begin{array}{c}\text { Cumulative Incidence } \\
\text { Rates/10,000 population }\end{array}$ & $\begin{array}{c}\text { CFR } \\
(\%)\end{array}$ \\
\hline 2000 & 517 & 36 & $8,003,388$ & 0.6 & 7.0 \\
2001 & 393 & 22 & $8,227,483$ & 0.5 & 5.6 \\
2002 & 61 & 11 & $8,457,852$ & 0.1 & 18.0 \\
2003 & 6 & 1 & $8,694,672$ & 0.0 & 16.7 \\
2004 & 1516 & 117 & $8,938,123$ & 1.7 & 7.7 \\
2005 & 3821 & 107 & $9,188,390$ & 4.2 & 2.8 \\
2006 & 3242 & 219 & $9,445,665$ & 3.4 & 6.8 \\
2007 & 8346 & 311 & $9,710,144$ & 8.6 & 3.7 \\
2008 & 513 & 32 & $9,958,190$ & 0.5 & 6.2 \\
2009 & 1294 & 9 & $10,237,019$ & 1.3 & 0.7 \\
2011 & 3 & 0 & $10,818,318$ & 0.0 & 0.0 \\
2012 & 7147 & 127 & $11,121,231$ & 6.4 & 1.8 \\
Total & 26859 & 992 & $112,800,475$ & 2.4 & 3.7 \\
\hline
\end{tabular}

CFR, case fatality rate. Source: Adapted from WHO annual summaries.

Table 2. Cholera incidence and case fatality rate in Guinea by prefectures from 2003-2009 outbreaks.

\begin{tabular}{|c|c|c|c|c|c|c|}
\hline Region and Prefecture & Cases (\%) & Deaths (\%) & $\begin{array}{c}\text { Number } \\
\text { of } \\
\text { outbreak } \\
\text { in } 7 \text { years }\end{array}$ & $\begin{array}{c}\text { Estimated } \\
\text { population } \\
\text { in } \\
2008 \\
\end{array}$ & $\begin{array}{l}\text { Cumulative incidence } \\
\text { rate } \\
\text { per } 10,000 \text { population. }\end{array}$ & $\begin{array}{l}\text { Case fatality rates } \\
\text { (\%) }\end{array}$ \\
\hline \multicolumn{7}{|l|}{ Boké } \\
\hline Boké & $\begin{array}{c}1087 \\
(5.8 \%)\end{array}$ & 25 (3.2\%) & 5 & 410,700 & 26.5 & 2.3 \\
\hline Boffa & $881(4.7 \%)$ & 35 (4.6\%) & 4 & 218,800 & 40.3 & 4.2 \\
\hline Fria & 319 (1.7\%) & $18(2.2 \%)$ & 1 & 114,300 & 27.9 & 5.5 \\
\hline Gaoual & $9(0.05 \%)$ & 0 & 1 & 192,300 & 0.5 & 0.0 \\
\hline Koundara & 0 & 0 & 0 & 126,100 & 0.0 & \\
\hline \multicolumn{7}{|l|}{ Conakry } \\
\hline 5 communes & $8657(46.2)$ & $\begin{array}{c}279 \\
(35.0 \%)\end{array}$ & 7 & $1,527,400$ & 56.7 & 3.2 \\
\hline \multicolumn{7}{|l|}{ Kindia } \\
\hline Dubréka & $\begin{array}{c}1649 \\
(8.8 \%)\end{array}$ & $40(5.0 \%)$ & 5 & 183,500 & 89.9 & 2.4 \\
\hline Kindia & $\begin{array}{c}1012 \\
(5.4 \%)\end{array}$ & $52(6.5 \%)$ & 6 & 401,900 & 25.2 & 5.1 \\
\hline Coyah & $\begin{array}{c}1031 \\
(5.5 \%)\end{array}$ & $29(3.6 \%)$ & 5 & 119,000 & 86.6 & 2.8 \\
\hline Forécariah & 937 (5.0\%) & $48(6.0 \%)$ & 4 & 273,700 & 34.2 & 5.1 \\
\hline Télimélé & $37(0.2 \%)$ & 15 (1.9\%) & 2 & 319,200 & 1.2 & 40.4 \\
\hline \multicolumn{7}{|l|}{ Labé } \\
\hline Lélouma & $37(0.2 \%)$ & $14(1.7 \%)$ & 1 & 191,800 & 2.0 & 36.1 \\
\hline $\begin{array}{l}\text { Mali, Tougué, Koubia et } \\
\text { Labé }\end{array}$ & 0 & 0 & 0 & 925,800 & & \\
\hline
\end{tabular}




\begin{tabular}{|c|c|c|c|c|c|c|}
\hline \multicolumn{7}{|l|}{ Mamou } \\
\hline Pita & $252(1.4 \%)$ & $25(3.2 \%)$ & 1 & 334,300 & 7.8 & 9.7 \\
\hline Dalaba & $150(0.8 \%)$ & $11(1.4 \%)$ & 2 & 191,000 & 7.8 & 7.4 \\
\hline Mamou & 0 & 0 & 0 & 330,300 & 0.0 & \\
\hline \multicolumn{7}{|l|}{ Faranah } \\
\hline Faranah & 375 (2.0\%) & 15 (1.9\%) & 1 & 205,900 & 18.2 & 4.0 \\
\hline Kissidougou & 206 (1.1\%) & 19 (2.4\%) & 1 & 288,900 & 7.1 & 9.3 \\
\hline Dabola & $9(0.05 \%)$ & $3(0.4 \%)$ & 1 & 155,600 & 0.6 & 34.0 \\
\hline Dinguiraye & 0 & 0 & 0 & 192,000 & 0.0 & \\
\hline \multicolumn{7}{|l|}{ Nzérékoré } \\
\hline Guékédou & 17 (9.6\%) & 127 (15.9\%) & 3 & 485,700 & 37.0 & 7.0 \\
\hline Lola & $75(0.4 \%)$ & $22(2.8 \%)$ & 1 & 187,700 & 4.0 & 29.7 \\
\hline Nzérékoré & $56(0.3 \%)$ & $6(0.8 \%)$ & 1 & 396,100 & 1.4 & 11.3 \\
\hline Macenta & $2(0.01 \%)$ & 0 & 0 & 389,600 & 0.0 & 0.0 \\
\hline Yomou et Beyla & 0 & 0 & 0 & 425,800 & 0.0 & \\
\hline \multicolumn{7}{|l|}{ Kankan } \\
\hline Kankan & $15(0.08 \%)$ & $4(0.5 \%)$ & 1 & 366,600 & 0.08 & 26.6 \\
\hline Mandiana, Siguiri, Kouroussa and Kérouané & 0 & 0 & 0 & $1,047,100$ & 0 & \\
\hline Guinée & $18,738(100 \%)$ & 796 (100\%) & & $10,001,100$ & 18.7 & 4.2 \\
\hline
\end{tabular}

2009 (Table 2). The most affected area was Conakry where all the seven epidemics took place, followed by Dubreka and Coyah which had 5 epidemics each. Boffa and Forécariah, each underwent 4 outbreaks. Three outbreaks happened in Guékédou. Dalaba and Télimélé each had 2 outbreaks.

As for 15 October 2012 (Table 3), the Cholera outbreak had resulted in the reporting of a total of 7,147 cases of cholera and 127 deaths: a case fatality ratio (CFR) of approximately 1.8\%. Cases and deaths were reported in 12 prefectures out of 34: Conakry, Coyah, Forecariah, Fria, Boffa, Dubréka, Boké, Mamou, Kindia, Kankan, and Kerouané. The largest incidence rate was found in Coyah, where the estimated incidence was 78.0 per 10,000 population, followed by Fria (43.4 per 10,000 population), Conakry (41.9 per 10,000 population), and Dubréka (25.7 per 10,000 population. Boffa and Forecariah closely had 17.6 per 10,000 population and 17.4 per 10,000 population respectively. Dabola had the lowest incidence rates estimated as 1.1 per 10,000 population (Table 3). In contrast to the incidence rate, Case fatality rate contributed to the highest incidence rates in Dabola (15.4\%) followed by Kankan (9.4\%), Mamou (8.9\%), and Forecariah (8.5\%). Conakry supported the lowest incidence rates $(0.5 \%)$ (Table 3$)$.

Looking at the periods of high intensity from Figure 1, a clear trend can be observed with cases increasing in week 29 (128 cases), peaking in week 34 (1152 cases). After week 34, the cases started dropping gradually throughout the week 41 (41 cases).

\section{Discussion}

Cholera is still a life-threatening disease in Guinea with frequent outbreaks and the reporting of sporadic cases throughout the year. This study raised an important point, the case fatality rate showed somewhat increasing trend over time which may be likely imputable to the inaccessibility of much of the country, the lack of health care services in places and the general unpreparedness for cholera outbreak. This premise is also sustained by the latest cholera outbreak in Guinea, in 2012, where the differences in case fatality rates between the relatively 
Table 3. Cholera incidence and case fatality rate in Guinea by prefectures from 2003-2009 outbreaks.

\begin{tabular}{|c|c|c|c|c|}
\hline Region and prefecture & Cases number & Deaths number & Cumulative incidence rate per 10,000 population. & Case fatality rates (\%) \\
\hline Conakry & $4583(64.1 \%)$ & $24(18.9 \%)$ & 41.9 & 0.5 \\
\hline Coyah & $664(9.3 \%)$ & $10(7.9 \%)$ & 78.0 & 1.5 \\
\hline Forecariah & $340(4.8 \%)$ & $29(22.8 \%)$ & 17.4 & 8.5 \\
\hline Fria & $355(5 \%)$ & $10(7.9)$ & 43.4 & 2.8 \\
\hline Boffa & $275(3.8)$ & $11(8.7 \%)$ & 17.6 & 4.0 \\
\hline Dubréka & $337(4.7 \%)$ & $7(5.5 \%)$ & 25.7 & 2.1 \\
\hline Boké & $210(2.9 \%)$ & $8(6.3)$ & 7.1 & 3.8 \\
\hline Mamou & $123(1.7 \%)$ & $11(8.7)$ & 5.2 & 8.9 \\
\hline Kindia & $121(1.7 \%)$ & $4(3.1 \%)$ & 4.2 & 3.3 \\
\hline Kankan & $53(0.7 \%)$ & 5 (3.9\%) & 2.0 & 9.4 \\
\hline Kerouané & $73(1 \%)$ & $6(4.7 \%)$ & 5.8 & 8.2 \\
\hline Dabola & $13(0.2 \%)$ & $2(1.6)$ & 1.1 & 15.4 \\
\hline Total & $7147(100 \%)$ & 127 (100\%) & 23.3 & 1.8 \\
\hline
\end{tabular}

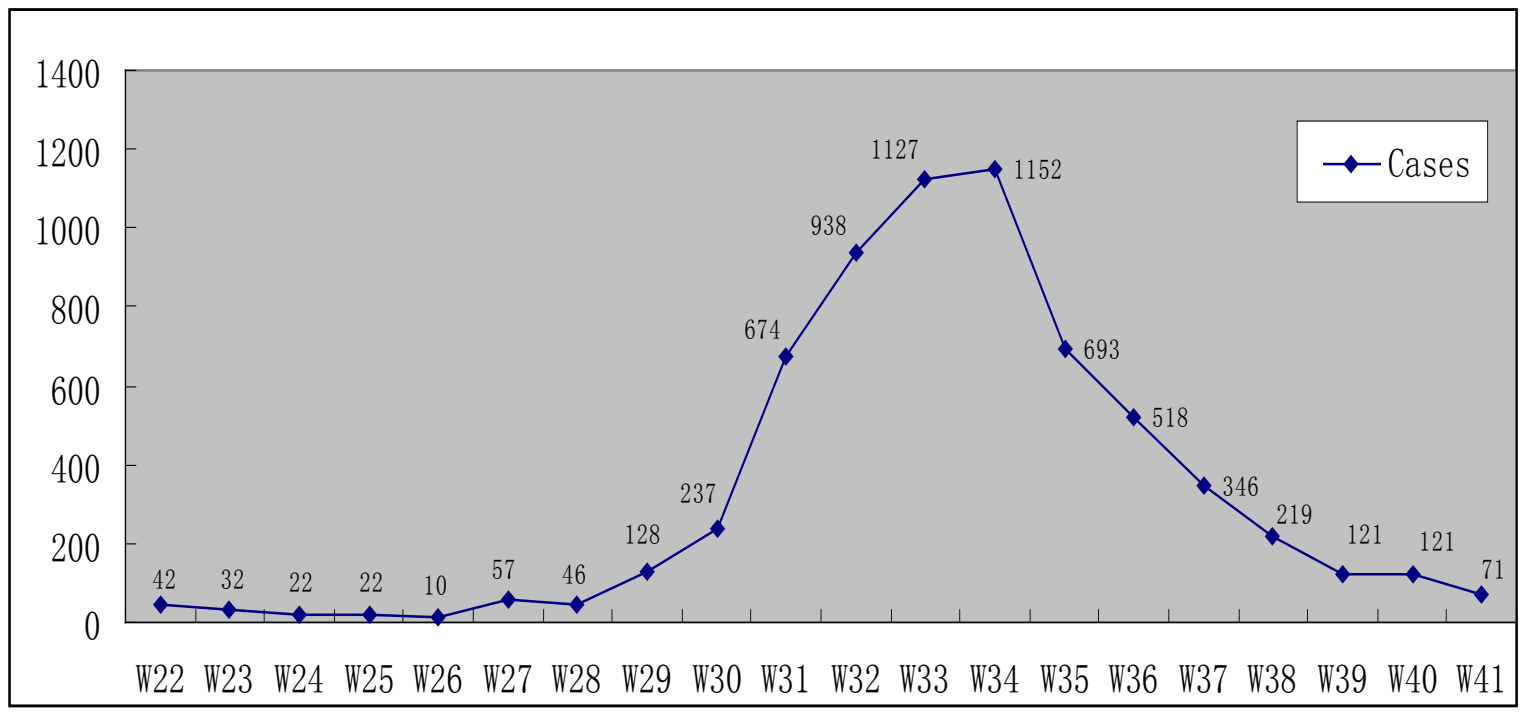

Figure 1. Weekly new cholera cases in Guinea, week 22 - 41 (2 February-15 October), 2012.

well-serviced National Capital city of Conakry (0.5\%) and more remote prefectures such as Dabola (15.4\%).

Other relevant findings of this study is the increasing temporal trends in the cholera incidence rates in Guinea; on the other hand, Conakry and the surrounding regions on the coastal strip are the hub and the starting point of cholera outbreaks from where the disease spreads to the remainder of the country. These findings suggest that a great deal of people continue to have inadequate or no water and sanitation. It is reported that more than one in seven children under five die each year in Guinea, many from diseases caused by the lack of hygiene and the poor quality of water [34].

Despites the proximity to cholera high-prevalence countries such as Sierra Leone [35]-[37], internal displacement and sub-regional instability [38] which can entail the spread of the disease, a number of common factors suggest possible sustained transmission and spread of cholera across the country. Continuous daily influx of traders and rural poor migrating to urbanized and commercialized cities with the hope of better life where sani- 
tation is drastically lacking has led to the creation of many open uncontrolled dump sites very close to community centers. In these public refuse dumps are discarded significant human excreta from disposable diapers, roadways, streets, and areas which are swept by public sweepers. Etiological studies have proved that $V$. cholerae survives well in faecal specimens if kept moist [39]. Newspapers often report that in Conakry there are many dwellers whose waste from public latrines are dumped in nearby rubbish tips or linked to a sewage system or directly into the sea [40] [41]. In the period of cholera outbreak, runoff water from open dumps sites during downpour may drain the bacteria into nearby wells, streams and surface water bodies. Since there has been no systematic water quality surveillance to date in Guinea [42], during such periods, the transmission of the bacteria can be perpetuated when people exploits these contaminated water bodies for cooking, drinking, bathing and other daily activities. In 1992, in Guinea, about $50 \%$ of people with access to piped water reported using well water as their primary alternate source of drinking water when the system is not working [43].

Another reason which drives cholera spread in Guinea might be attributed to fish trade. In coastal areas of the country, including the capital, Conakry, fish has been proved to be an effective cholera host, passing it on through their faeces at markets across the city [42]. The coastal link of cholera as an estuarine reservoir for $V$. cholerae has been established previously [44]. This analysis also demonstrated that the latest outbreak of cholera in Guinea in 2012 had a seasonal pattern of occurrence with peak of disease observed in the rainy season. Similar peaks have been seen in previous years [45] which seem to be probably epidemiologically relevant. The abundant precipitation in the rainy season likely facilitates transmission of infectious $V$. cholerae in the densely populated areas in the same insalubrious situations as described above should have led to cholera peak. Average annual rainfall in Conakry is about 4.2 meters [46]. There has also long been a clear connection between the epidemic peak of cholera and the amount of rainfall, as truly as the weekly number of cases of cholera during the rainy season (July-August) in Guinea [19]. Cholera appears to mostly affect populations living in low-lying flat areas especially those with high water table and where the water is brackish [20] [47].

Our study has some limitations. The number of individuals affected might be often underestimated due to the reporting bias or poor laboratory facilities for diagnosis in the remote areas. At some point in the past due to socio-political turmoil [48]-[50], the normal collection of health data may have been interrupted which could result in underreporting of cholera cases and deaths. In addition, WHO has observed an incomplete notification of cholera cases and poorly functioning surveillance systems in some parts of the world (particularly in Africa) contributing to the underreporting of cases [51]

To minimize the risk of cholera infection, the following measures are recommended: Giving the communities improved water quality and proper sanitation systems. Specially, as interventions to make people accessed to safe water systems in developing countries indicated that these can be implemented at low cost [52]. Add to the above recommendation, proper management for the collection, storage and disposal of refuse from domestic and street should be instituted. On-going disease surveillance and early reporting of cholera cases will facilitate epidemiological investigation and outbreak detection. Measure should be taken to enforce food and environmental regulations so as to maintain a high standard of food safety, and to provide trainings for food handlers. Close sub-regional collaboration and monitoring of cholera outbreaks in neighboring countries should be constituted to avoid cross-border spread. Raising the awareness of general public about the risks of cholera infection through various channels and promoting the importance of good personal hygiene will be of great importance.

\section{Conclusion}

In summary, cholera is an important health problem in Guinea. Any earnest attempts to improve water and sanitation alongside with promotion of good hygienic practices will likely ward off the threat of cholera in the country.

\section{Funding}

The study was carried out with the fund support of Fundamental Research Funds for the Central Universities of Central South University in China (project number: 2012zzts029).

\section{Conflict of Interest}

The authors have stated explicitly that there are no conflicts of interest. 


\section{Acknowledgements}

The authors thank Central South University in China, The World Health Organization (WHO), and the Guinean Ministry of Public Health for their contributions to this study.

\section{References}

[1] Wikipedia, the Free Encyclopedia. Wikipedia Contributors: Cholera. http://en.wikipedia.org/wiki/Cholera

[2] Mouriño-Pérez, R.R. (1998) Oceanography and the Seventh Cholera Pandemic. Epidemiology, 9, 55-357.

[3] WHO (2009) Weekly Epidemiological Record, 84, 309-324.

[4] WHO (2010) Weekly Epidemiological Record, 85, 293-308.

[5] Barua, D. (1972) The Global Epidemiology of Cholera in Recent Years. Journal of the Royal Society of Medicine, 65, 423-428.

[6] Cvjetanovic, B. and Barua, D. (1972) The Seventh Pandemic of Cholera. Nature, 239, 137-138. http://dx.doi.org/10.1038/239137a0

[7] Goodgame, R.W. and Greenough, W.B. (1975) Cholera in Africa: A Message for the West. Annals of Internal Medicine, 82, 101-106. http://dx.doi.org/10.7326/0003-4819-82-1-101

[8] Boiro, M.Y., Lama, N., Barry, M., Diallo, R. and Morillon, M. (1999) The Epidemic of Cholera in Guinea: 1994-1995. Tropical Medcine, 59, 303-306.

[9] Bertrand, S. and Didier, B. (2009) Epidemiology and Evaluation of Early Warning System of Cholera in Guinea. Mission Report, UNICEF.

[10] WHO (2001) Weekly Epidemiological Record, 76, 233-240.

[11] WHO (2002) Weekly Epidemiological Record, 77, 257-268.

[12] WHO (2003) Weekly Epidemiological Record, 78, 269-276.

[13] WHO (2004) Weekly Epidemiological Record, 79, 281-288.

[14] WHO (2005) Weekly Epidemiological Record, 80, 261-268.

[15] WHO 2006) Weekly Epidemiological Record, 81, 297-308.

[16] WHO (2007) Weekly Epidemiological Record, 82, 273-284.

[17] WHO (2008) Weekly Epidemiological Record, 83, 269-284.

[18] WHO (2012) Weekly Epidemiological Record, 87, 289-304.

[19] Medecins Sans Frontieres (MSF) Doctor without Boarders (2012) Use of Oral Cholera Vaccine in Response to an Epidemic in Guinea. Immunization Coverage Surveys. Doctor without Boarders, Conakry.

[20] Clarke, G.R.G. and Menard, C. (1999) A Transitory Regime Water Supply in Conakry, Guinea, World Bank Policy Research Working Paper No. 2362, p. 11.

[21] Deen, J.L., von Seidlein, L., Sur, D., Agtini, M., Lucas, M.E.S., Lopez, A.L., et al. (2008) The High Burden of Cholera in Children: Comparison of Incidence from Endemic Areas in Asia and Africa. PLOS Neglected Tropical Diseases, 2, e173. http://dx.doi.org/10.1371/journal.pntd.0000173

[22] Griffith, D.C., Kelly-Hope, L.A. and Miller, M.A. (2006) Review of Reported Cholera Outbreaks Worldwide, 19952005. American Journal of Tropical Medicine and Hygiene, 75, 973-977.

[23] Koelle, K. and Pascual, M. (2004) Disentangling Extrinsic from Intrinsic Factors in Disease Dynamics: A Nonlinear Time Series Approach with an Application to Cholera. The American Naturalist, 163, 901-913. http://dx.doi.org/10.1086/420798

[24] Koelle, K., Rodó, X., Pascual, M., Yunus, M. and Mostafa, G. (2005) Refractory Periods to Climate Forcing in Cholera Dynamics. Nature, 436, 696-700. http://dx.doi.org/10.1038/nature03820

[25] Ciglenecki, I., Sakoba, K., Luquero, F.J., Heile, M., Itama, C., Mengel, M., et al. (2013) Feasibility of Mass Vaccination Campaign with Oral Cholera Vaccines in Response to an Outbreak in Guinea. PLoS Medicine, 10, e1001512. http://dx.doi.org/10.1371/journal.pmed.1001512

[26] Africa Region Human Development (2006) Guinea: A Country Status Report on Health and Poverty. Working Paper Series No. 45.

http://siteresources.worldbank.org/INTAFRREGTOPEDUCATION/Resources/444659-1212165766431/H_CSR_Guin ea.pdf

[27] IRIN News (2012) Guinea-Sierra Leone: Cholera-Rising with the Downpours. IRIN News. 
http://article.wn.com/view/2012/08/31/GUINEASIERRA_LEONE_Cholera_rising_with_the_downpours_q/

[28] IRIN News (201) GUINEA: New Cholera Strain Poses Prevention Challenges. IRIN News. http://www.irinnews.org/Report/97068/GUINEA-New-cholera-strain-poses-prevention-challenges

[29] Cash, R.A. and Narasimhan, V. (2000) Impediments to Global Surveillance of Infectious Diseases: Consequences of Open Reporting in a Global Economy. Bulletin of the World Health Organization, 78, 1358-1367.

[30] Kirigia, J.M., Sambo, L.G., Yokouide, A., Soumbey-Alley, E., Muthuri, L.K., et al. (2009) Economic Burden of Cholera in the WHO African Region. BMC International Health and Human Rights, 9, 1-14.

[31] National Coordination Unit for EPI/PHC/ME Immunization Section, Ministry of Public Health (2005) Financial Sustainability Plan of the Expanded Program on Immunization 2005-2013. The Ministry of Public Health of Guinea, Conakry.

[32] Department of National Health Information, Ministry of Public Health of Guinea (2002) National Health Development Plan 2003-2012. The Ministry of Public Health of Guinea, Conakry.

[33] Department of National Health Information, Ministry of Public Health of Guinea (2009) Guinean Annual Health Statistics Report 2008. The Ministry of Public Health of Guinea, Conakry.

[34] Bally, E. (2012) At a Glance: Guinea. Promoting Hygiene and Water Treatment to Prevent Deadly Diseases in Guinea. UNICEF News. http://www.unicef.org/infobycountry/guinea 53091.html

[35] The Telegraph (2012) Sierra Leone Battles Worst Cholera Outbreak in 15 Years. The Telegraph News. http://www.telegraph.co.uk/news/worldnews/africaandindianocean/sierraleone/9507802/Sierra-Leone-battles-worst-ch olera-outbreak-in-15-years.html

[36] NaTHNaC (2012) Cholera Outbreak in Sierra Leone. NaTHNaC News. http://www.nathnac.org/pro/clinical updates/cholera sierra leone 220812.htm

[37] Center for Disease Control and Prevention (2003) Cholera Epidemic after Increased Civil Conflict: Monrovia, Liberia. Weekly Report, 52, 1093-1095.

[38] The Oxonian Globalist (2012) Instability in Mali. Futurechallenges News. http://futurechallenges.org/local/instability-in-mali/

[39] Sack, D.A., Sack, R.B., Nair, G.B. and Siddique, A.K. (2004) Cholera. The Lancet, 365, 1.

[40] IRIN News (2012) GUINEA: Conakry Residents Demand Cholera Vaccine. IRIN News. http://www.irinnews.org/printreport.aspx?reportid=96301

[41] Guardian News (2012) West Africa Desperate for Cleaner Toilets to Save Slums from Cholera. Guardian News. http://www.guardian.co.uk/global-development/2012/aug/20/west-africa-toilets-slums-cholera

[42] IRIN News (2012) GUINEA: Evading the Cholera Epidemic. IRIN News. http://www.irinnews.org/Report/94449/GUINEA-Evading-the-cholera-epidemic

[43] Durany, J. and L'huissier, A.M. (1994) The Urban Environment in Conakry: Behavior, Attitudes and Practices of Households. UNDP-World Bank Water and Sanitation Project, Abidjan.

[44] Alam, M., Islam, A., Bhuiyan, N.A., Rahim, N., Hossain, A., Khan, G.Y., et al. (2011) Clonal Transmission, Dual Peak, and Off-Season Cholera in Bangladesh. Infection Ecology and Epidemiology, 1, 7273. http://dx.doi.org/10.3402/iee.v1i0.7273

[45] WHO, Cholera Country Profile, Guinea (2007) Global Task Force on Cholera Control.

[46] World Bank (1990) Republic of Guinea: Country Economic Memorandum. Volume II: Sectoral Analysis. World Bank, Washington DC.

[47] Mayala, B.K., Mboera, L.E.G. and Gwacha, F. (2003) Mapping of Cholera Risks Using Geographical Information System in Llala City, Tanzania. Tanzania Health Research Bulletin, 5, 8-12.

[48] Libcom News (2007) Guinea: Police Clash with General Strike. Libcom News. http://libcom.org/news/guinea-police-clash-with-general-strike-17012007

[49] Reuters (2007) Guinea General Strike Resumes. Reuters. http://www.talktalk.co.uk/news/world/reuters/2007/02/12/guinea-general-strike-resumes.html

[50] Reuters (2007) More than 20 killed in Guinea Strike Violence. Reuters. http://www.reuters.com/article/idUSL2279240020070122

[51] WHO. Department of Communicable Disease Surveillance and Response. WHO Report on Global Surveillance of Epidemic-prone Infectious Disease. WHO/CDS/CSR/ISR/2000.1

[52] Reiff, F.M., Roses, M., Venczel, L., Quick, R. and Witt, V.M. (1996) Low Cost Safe Water for the World: A Practical Interim Solution. Journal of Public Health Policy, 17, 389-408. http://dx.doi.org/10.2307/3343099 
K. Mamady, S. Mafoule

\section{Abbreviations}

WHO, World Health Organization; UNICEF, United Nations Children’s Fund; NGO, Non-Governmental Organization. 
Scientific Research Publishing (SCIRP) is one of the largest Open Access journal publishers. It is currently publishing more than 200 open access, online, peer-reviewed journals covering a wide range of academic disciplines. SCIRP serves the worldwide academic communities and contributes to the progress and application of science with its publication.

Other selected journals from SCIRP are listed as below. Submit your manuscript to us via either submit@scirp.org or Online Submission Portal.
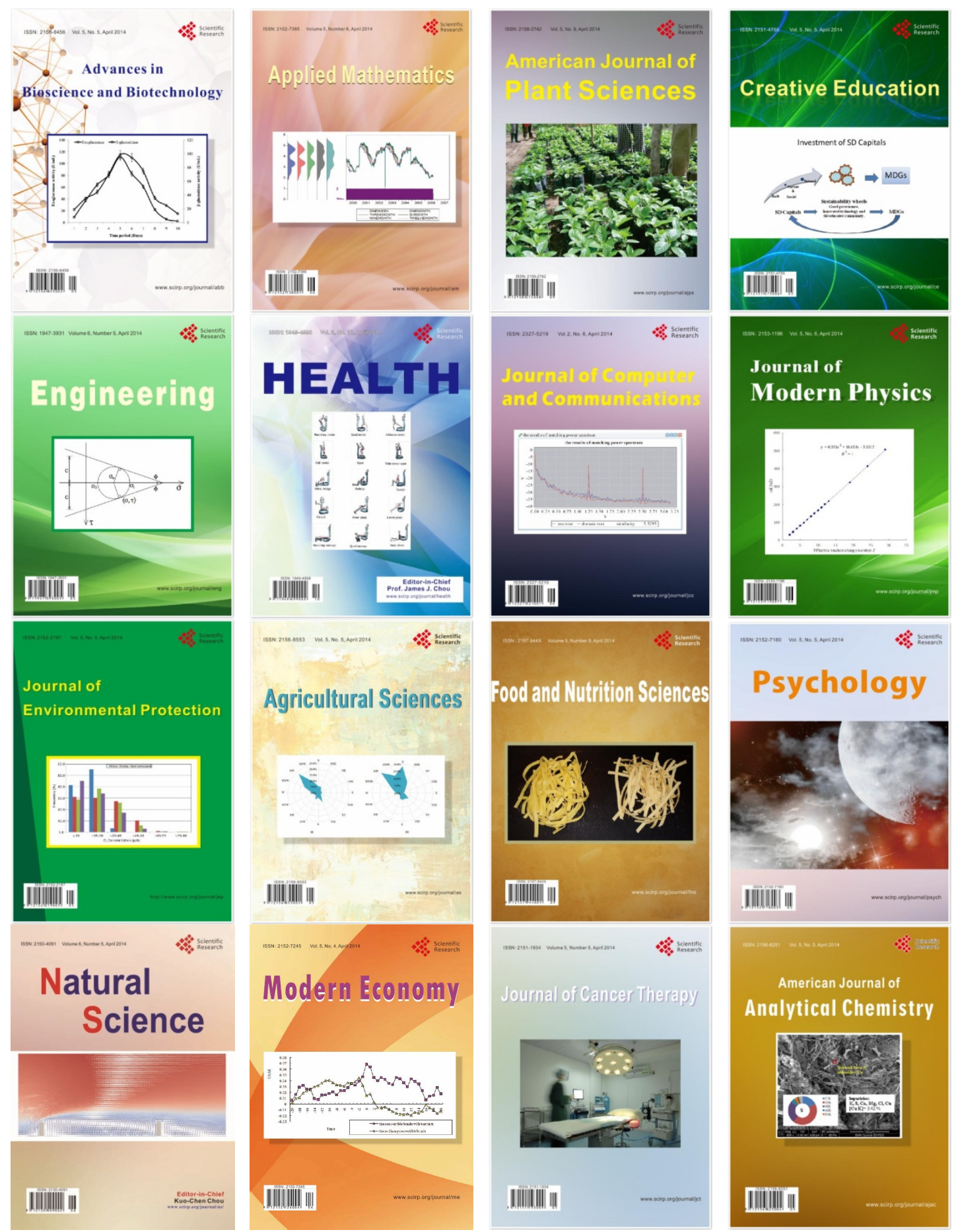